Apuntes Universitarios, 2021: 11(1), enero-marzo

ISSN: 2304-0335 DOI: https://doi.org/10.17162/au.v11i1.546

\title{
Etnografía y folclore de los Yakuts en las obras de A. E. Kulakovsky en el contexto de la textología
}

\author{
Ethnography and folklore of the Yakuts in the works of A. E. Kulakovsky in the context \\ of textology
}

Praskovia Sivtceva-Maksimova ${ }^{1 \mathrm{a}}$

M.K. Ammosov North-Eastern Federal University, Yakutsk, Russia ${ }^{1}$

(iD) Orcid: https://orcid.org/0000-0001-7827-9177

Recibido: 03 de julio de 2020

Aceptado: 07 de octubre de 2020

\begin{abstract}
Resumen
La relevancia de la presente investigación se revela en el estudio de los trabajos introducidos en términos de textología en las obras del poeta A. E. Kulakovsky. El análisis de las conclusiones conceptuales, relacionadas con la cultura del pueblo Sakha, proporciona la sustanciación de los nuevos hechos de la biografía y personalidad del escritor, quien desempeñó una misión histórica especial en la vida espiritual de la sociedad. Por ende, el objetivo del estudio es ampliar los parámetros de la argumentación científica de los textos analizados de Kulakovsky, a fin de revelar el significado de sus primeras publicaciones. Los autores de la presente investigación aplican métodos culturológicos y hermenéuticos de la filología en el contexto del análisis tipológico comparativo de los textos, fuentes y documentos. Los resultados del estudio sugieren la confirmación del concepto de discurso de Kulakovsky como narrativa, introducido en sus trabajos sobre etnografía y folklore. La sistematización de los escritos del mencionado autor se sitúa en la intersección de los problemas de la lingüística, la psicología cognitiva y la sociología. Vale la pena destacar que la presencia de los elementos prácticos de la cultura cristiana en las creencias de Sakha y en la obra de Kulakovsky.
\end{abstract}

Palabras clave: Sahka, Kulakovsky, poesía, Yakut, hermenéutica, filología, folklore

\begin{abstract}
The relevance of the present investigation is revealed in the study of the works introduced in terms of textology in the works of the poet A. E. Kulakovsky. The analysis of the conceptual conclusions, related to the culture of the Sakha people, provides the substantiation of the new facts of the biography and personality of the writer, who performed a special historical mission in the spiritual life of the society.Therefore, the objective of the study is to expand the parameters of the scientific argumentation of the analyzed texts of Kulakovsky, in order to reveal the meaning of his first publications. The authors of the present investigation apply cultural and hermeneutical methods of philology in the context of the comparative typological
\end{abstract}


analysis of texts, sources and documents. The results of the study suggest the confirmation of Kulakovsky's concept of discourse as narrative, introduced in his works on ethnography and folklore. The systematization of the writings of the mentioned author is situated at the intersection of the problems of linguistics, cognitive psychology and sociology. It is worth noting that the presence of the practical elements of Christian culture in the beliefs of Sakha and in the work of Kulakovsky.

Keywords: Sahka, Kulakovsky, poetry, Yakut, hermeneutics, philology, folklore

\section{Introduction}

The works of Kulakovsky, A.E. (1877-1926) in ethnography, folklore, and the Yakut language represent the studies by the expert of the original culture of the peoples of the Northeastern region of Russia. He collected the most valuable sources for studying the beliefs and oral folklore of the Yakuts, legends, historical and ethnographic traditions throughout the vast territory of Yakutia and outside.

Kulakovsky's professionalism as a collector is revealed in the discussions on the materials classification; in understanding the peculiarities of the folklore texts corpus, their role and significance in living folk speech, as well as in the methods of ethnography and folklore research described at the intersection of the problems of linguistics, cognitive psychology, and sociology. The scientist's deep knowledge of folk culture, language, and lifestyle is confirmed in the work "To the Yakut intelligentsia" (Sivtceva-Maksimova, 2016). The competence in scientific methods of analysis forms the basis for the study of the flora and fauna of the northern regions of Russia (Sivtceva-Maksimova and Sivtceva, 2019), and for the compilation of dictionaries and reference books. The integrity of the intellectual heritage of the classic of the Yakut literature is confirmed by the contemporary researchers' interest in his works and by their numerous translations. In this context, it is worth highlighting the translation of the poem "Shaman's Dream" into Japanese (Suzuki, 2015) and "The Debate between the Mind and the Heart" into Serbian (Kulakovsky, 2019).

The goal of the study is to extend the parameters of argumentation in Kulakovsky's works as logically verified scientific provisions that reveal the author's conclusions in the context of relevant socio-historical problems. In this regard, the distinguishing feature of his scientific works is the obligatory presence of prefaces that reveal comprehensively and convincingly the principles of the materials systematization as facts of the real state of the studied phenomena. The function of the preface is rather to clarify the perspectives of culturological studies, to deepen and expand the evidence consistently, to substantiate the main conclusions, including reflection on the prospects for further work in specific areas of knowledge than to reason the goal of the study.

The relevance of the research is determined by the study of Kulakovsky's works in terms of textology, focusing on the particular facts in the history of his text publications, and the 

analysis of their structure. In addition, the personality of the author, who performed a special historical mission in the spiritual life of the society, is represented in new perspectives.

\section{Goal and hypotheses}

The goal of the present research is determined by the intent to study Kulakovsky's scientific works in terms of systematization of particular practical results of a comparative analysis of early works publications on ethnography and folklore; to reveal the significance of the first publications; to introduce the fragments of the main inconsistency of the lifetime edition of proverbs and sayings as a completed scientific work. The novelty of the conducted analysis is the confirmation of the hypothesis of the logical interrelation of early publications as a verification of the first publications significance, including N. Tolokonsky's edition, which is currently considered as the fact of authorship attribution by another person.

\section{Materials and methods}

The author of the present research applied the culturological and hermeneutic methods of philology in the contexts of the textual and comparative-typological analysis of scientific works, sources, and documents. The methodological basis of the study comprised the works of P.G. Bogatyrev, which substantiated the functional-structural and hermeneutic methods for the fixation and analysis of folklore texts; contemporary materials of collective publications of IWL RAS on textology and problems of comparative literature studies and folklore; as well as the works of M.I. Shcherbakova, E.A. Kozhemyakin, and I.A. Tarasova on the analysis of academic publications, poetics, theory of discourse and narratology.

The methods of P.G. Bogatyreva in the study of folklore and ethnographic materials is based on the study of "living tradition and the components of factors, taking into account the deep penetration into the structure of the text and its situational connections" (Bogatyrev, 2006) as part of folk culture. In this regard, the scientific heritage of Kulakovsky contains facts confirming the importance of the author's principle in the systematization of materials and the posing of controversial questions in assessing the research of his contemporaries. National origins are obvious in Kulakovsky's works: the strategy of his texts lies in the social orientation of their form and content, where discourse as a systematization of analytical observations does not exclude the presence of "cognitive narratology - the study of mentally significant relationships in narrative practices" (Tarasova, 2018).

\section{Discussion}


The creative competence of discourse forms the basis of the dialogical concept in Kulakovsky's "Materials on the study of the beliefs of the ancient Yakuts". In the preface, the researcher points out the following: "The religion of the ancient Yakuts is almost completely forgotten due to the absence of writing system and the introduction of Christianity. Only miserable fragmentary data from religious beliefs remained in the memory of the people, and that only from the area of the external, ritual side. As for the internal content and ethical side, this part is completely lost in the deep darkness of the obscurity" (Kulakovsky, 1979).

Kulakovsky considers the work of V.F. Troshchansky "The evolution of the black faith (shamanism) among the Yakuts" (1902) as "the only valuable and serious work on the issue". However, he does not agree with the author's conclusion that "the principles of goodness and justice are not inherent to the Yakut gods". In Troshchansky's work we find the following statement: "The beliefs preconditioned by the good powers ... began to weaken long before the adoption of Christianity by the Yakuts, being replaced by the beliefs based on dark, hostile powers ... However, from the surviving remnants, we understand that the Yakut beliefs sometimes had a deep philosophical basis" (Troshchansky, 1903).

The extreme unambiguity of Troshchansky's conclusions is explained by Kulakovsky as following: "He did not know the Yakut language and did not have extensive Yakut material." For this reason, Troshchansky's research was often based on occasional facts. In this regard, Kulakovsky clarifies the main direction and goal of his work: "In the materials I introduce, the reader will find a lot of opposition to these unflattering conclusions for the Yakuts" (Kulakovsky, 1979).

For the other hand, a sophisticated systematization of the materials reflects how the ancient beliefs of the Yakuts underwent changes or disappeared gradually in course of time due to the adoption of Christianity. The second paragraph of the second section on "higher beings, personifying the goodness" reads: "With the introduction of Christianity, the concept of the main and good god YuryungAyyiyi Toyon (Bright Majestic God / Lord) was mixed with the concept of a Christian God, who had the identical functions, at least in the essential matter, i.e., the creation of the World, kindness and justice. Therefore, Christian priests should have forbidden the newly converted to call the Lord God such a curly name as YuryungAyyiyi Toyon" (Light Creator / Creator Lord). However, "they agreed on the name Ayyiyi Toyon (Creator Lord), by which the Yakuts could freely mean, due to the meaning of the word "Ayyiyi", their main god YuryungAyyiyi Toyon".

This observation by Kulakovsky confirms the natural character of the adoption of Christianity by the Yakuts: "Thus, Ayyiyi Toyon did not exist separately from YuryungAyyiyi Toyon, as it was a name of a later origin (Christian era)" (Kulakovsky, 1979).

Concerning the relationship of Kulakovsky to Christianity, it can be additionally noted that Mousalimas, S.A. in the research on the significance of the missionary activities among 

as the enlighteners of the Sakha people (Mousalimas, 2004). Additional information on this fact of his biography can be found in the copies of the documents "Literature on the Orthodox Resurrection in Alaska" (The Alaskan Orthodox literary resurrection, n.d.).

This Kulakovsky's research introduces a classification that begins with the beliefs of special significance and ends with a characteristic of omens and fortunetellings from everyday life. The first section, "The Universe," presents a description of the three-tiered world in myths and olonkho. The author provides a clarification of the poetic imagery, where alliterative consonance allows metaphors expressed by quantitative attributes or comparisons in the description of each of the worlds, although they cannot be regarded as an exact identification of spatial concepts. As far as the heavenly bodies are concerned, Kulakovsky as a whole does not deny the influence of ancient myths on their perception by the Yakuts.

Beliefs about "supernatural beings", totems, the original perception of the human soul by the Yakuts are introduced in the second, third and fourth sections. The last of them reveals the meaning of three components of the human soul, which have been defining the unity of human and the environment from antiquity to nowadays. On this issue, Kulakovsky gives the following explanation of Troshchansky's speculations: "Troshchansky's hypothesis about these kuts (a general name for the human soul), in my opinion, is believable, although, of course, it is very hypothetical. Troshchansky says that at the conception of the child Ayyiyihyit (the ancient Sakha deity in the image of a woman that blesses the birth of a human) takes buorkut (clay soul) from the earth, salgynkut (air soul) from the air, attaches them to iyekut (the mother's soul) and implants everything into a woman. In fact, the ancient Yakuts noticed and became convinced that the human body after death turns to dust, i.e., to clay, that during life, a person breathes air, and cannot exist without this breath. Therefore, it is natural and understandable that the ancient Yakuts should have created and admitted the idea of "clay" and "air" souls, as elements necessary for human existence". At the beginning of this section, Kulakovsky writes about the "mother soul" of a human: "Iyekut" (the mother soul), is the main soul. At the conception of a child, it is implanted by the deities (through Ayyiyihyit or Ieyehsit, which is the personification of noble feelings in the image of a Woman) into a woman-mother." He confirms this idea with figurative words from folk songs and presents the following proof: "Iyekut is stolen and tormented by abaahyi (evil spirits), which causes people's diseases. After the death of a human, the soul travels to the next world. If the child is very frightened, his mother-soul "skits" ("kutystanar", compare with "the heart is in one's boots"); it makes him shy and painful for all his life" (Kulakovsky, 1979).

The analysis of Bogatyrev's scientific works allowed us to distinguish the following methodological guidelines: "To strive to explore the current state of folklore and ethnographic traditions; to take into account the variability of the national worldview; to describe and study 
the folklore, ethnographic and linguistic facts synchronically ; to divide the folklore fact into "elementary units" (Sorokina, 2006). It is worth highlighting that all these principles, which were equated by a prominent Russian researcher to the foundations of ethnography and folklore, were revealed in Kulakovsky's work "Materials on the study of the beliefs of the Yakuts."

\section{Results}

The results of the study consist in the presentation of the scientific works of A. Kulakovsky about the beliefs of the Sakha and traditional literature as a comparative analysis of his materials with the work of V. Troshchansky "The Evolution of the Black Faith of the Yakuts", the study of the history of early publications, analysis of the structure and prefaces in the systematization of proverbs, folk legends and sayings ... From this perspective, the features of Kulakovsky's scientific views on the issues of the peoples' culture, his principles and methods as a collector and researcher of ethnography and folklore are revealed.

In general, Kulakovsky's "Materials" reveal the author's concept in the forms of systematization of materials in the parameters of cognitive narratology. In this regard, discourse as a systematization of analytical observations is revealed by the synonym of "scientific speech aimed at studying the nature of things and society" and can be contrasted with "colloquial speech or everyday dialogues" (4, p. 5-6). On this basis, a well-thought-out classification of "Materials ..." is close to a narrative representation serving as one of the arguments for certain conclusions of the researcher. This term, referring to plot formation, does not exclude the presence of "archetypal components" in relation to the image at the level of "emotional foreknowledge" (11, p. 20-21). In the monographic work of I. A. Tarasova, this question is considered at the level of literary texts with the definition of the interdisciplinary status of this term in the works of other authors, who takes into account the "narratology of unnatural narratives" $(15 ;$ sixteen; 17$)$.

The referential competence of the discourse as a communicative resource of the "rhetorical worldview" is revealed in Kulakovsky's work "Yakut Proverbs and Sayings", published in 1925 containing 965 units of proverbs and 110 variations of them [Kulakovsky, 1925]. As you can see, in relation to the first edition, the number of proverbs has increased more than three times. The materials are given in the Yakut language (in alphabetical order) with the author's translation of the introdaction and the comments into Russian. Kulakovsky writes about the theoretical aspects of studying small forms of oral folk art, shares his experience in collecting and classifying materials, reveals the main methodological directions for their study.

He also gives a number of observations. Let's give two examples: a) "Reading some collection of proverbs, you cannot properly appreciate its value and admire them, because you are suppressed by the number and fragmentary thoughts. But in real life, when you hear a 

proverb appropriately applied to some occasion or person, there is great joy and admiration";

b) "I also discovered the unfortunate fact that the younger generation, especially the studying youth, knows an insignificant number of proverbs, and this indicates the oblivion of the Yakut language" (Kulakovsky, 1979, p. 102, 106).

Kulakovsky's conclusions confirm his unique understanding of the patterns of development and the living dynamics of a language, as well as his ability to make a deep analysis of the processes taking place in the everyday life of the society. But on the other hand, they serve as a proof of distancing himself from the political events associated with the revolution, because his fundamental conviction was the desire to preserve culture. He found a way to enlighten the people in their primordial spiritual traditions. On a similar note, we find the answer in the article about the classics of Abkhaz literature by D.I. Gulia, a comment on Kulakovsky: "The Patriarch never spoke out from radical position against the princes and nobles, did not demand their punishment. The unity of the people, their enlightenment, liberation from evil, the preservation and development of their native language and national culture, the development of literature - this is what he constantly thought about" (Biguaa, p. 201).

Caring for the preservation of the native language is the basis and source of his tireless continues research of the figurative speech as evidence of the spiritual identity of the Sakha people. Through everyday communication in very unique and diverse situations, Kulakovsky clarifies the natural element for the emergence and consolidation of special expressions in the form of units of oral speech. This fact confirms one of the main scientific provisions of P.G. Bogatyrev (1893-1971) on the role of the situational settings in folklore. If an outstanding scientist had the opportunity to get acquainted with the works of A.E. Kulakovsky, perhaps he would have considered the value of the experience of the Yakut folklorist as one of the conformations for his conclusion. For Kulakovsky's works on local forms of folklore reveal his ability to create an appropriate environment, which in itself is an organic part of the subject of his research, which corresponds to Bogatyrev's methodological provisions on the role of external objective circumstances in the study of folklore traditions. He refers to the setting for research as "the composition of the audience (adult audience, youth, children of different ages; family members, close acquaintances, strangers)", "the subjective state of the folklore performer" and other moments (Bogatyrev, p. 218). All these integrates are organically connects with the techniques and methods of Kulakovsky's work on the collection, systematization, and study of ethnographical and folklore materials.

\section{Conclusion}

The study of the Kulakovsky's works showed the significance of his scientific heritage on the classification of unique materials on the spiritual culture of the Sakha people. His deep 

of practical experience in the author's systematization of texts, taking into account social processes in society and the linguistic situation in a particular time period. On this basis, his findings were actualized and the interdisciplinary contexts of their analysis were expanded, taking into account the influence facts and the adoption of the practical elements of Christian culture in the Yakut beliefs, which were presented in his works. In addition, the practical aspects of the analysis / evaluation of his work on literature as a whole were revealed. The facts and observations introduced by Kulakovsky also reflected the scrupulosity of his collection work and the scientific approach to the subject of research, which characterized the peculiarity of his texts as an author's word addressed to the reader.

\section{References}

Biguaa, V.A. (2017). Abkhazian literature in the 20s of the 20th century. (The issues of the theory, history, and contemporary aspects).The issues of the national literatures study.Discourse of identity in changing contexts. Moscow: IWL RAS.

Bogatyrev, P.G. (2006). Functional and structural study of folklore (under-reported and unpublished works). Moscow: IWL RAS.

Fludernik, M. (2009). An introduction to narratology. London - N.Y.: Routledge.

Handbook of narratology. Berlin-N.Y.: Walter de Gruyter, 2009.

Herman, D. (2002). Story Logic: Problems and Possibilities of Narrative. University of Nebraska Press.

Kozhemyakin, E.A. (2008). Discourse-analysis as a cross-disciplinary methodology: historical aspect. Scientific bulletin, 15, 5-11.https://cyberleninka.ru/article/n/diskurs-analiz-kakmezhdistsiplinarnaya-metodologiya-istoricheskiy-aspekt

Kulakovsky, A. E. (1979). Scientific works. Yakutsk.

Kulakovsky, A.E. (1922). Materials on the study of the beliefs of the ancient Yakuts. Collection of the materials for the study of Yakutia, 1, 25-29.

Kulakovsky, A.E. (1923). Materials on the study of the beliefs of the Yakuts. Notes of the Regional Geographical Society, 1.

Kulakovsky, A.E. (2019). The Debate between the Mind and the Heart. Poem. Serbian illustrated folk calendar for the year 2019.

Kulakovsky, A.E. (1925). Yakut proverbs and sayings. Preface and the translation by the author. Collection of Proceedings of the "Sakha Keskile" Research Society. Yakutsk.

Mousalimas, S.A. (2004). From Mask to Icon: Transformation in the Arctic. Brookline: Holy Cross Greek Orthodox Press.

Shcherbakova, M.I. (2019). Serving a genius. From the history of the text to the history of the literature. Moscow: IWL RAS. 
Sivtceva-Maksimova, P. (2016).Letter "To the Yakut Intelligentsia" by A. E. Kulakovsky: setting and features of the problem of survival of indigenous peoples of the North. International Journal of Environmental \& Science Education, 11(18), 1149511503.https://files.eric.ed.gov/fulltext/EJ1121251.pdf

Sivtceva-Maksimova, P., Sivtseva, C. (2019). Toward the scientific research of A.E. Kulakovsky: floristic analysis of the northern region of Russia. Amazonia, 8, 365371.https://www.amazoniainvestiga.info/index.php/amazonia/article/view/113/89 Sorokina, S.P. (2006). Functional-structural method of Bogatyrev, P.G. Moscow: IWL RAS. Suzuki, D. (2015). Experience in translating the poem by A.E. Kulakovsky "Shaman's Dream" (1910) into Japanese.Culture and Language. The Faculty of Foreign Languages. Sapporo University.

Tarasova, I.A. (2018). Cognitive Poetics. Subject, terminology, methods. Moscow: INFRA-M. The Alaskan Orthodox literary resurrection. An interview with Reader Mikhail Ivanovich. https://pravoslavie.ru/29721.html

Tolokonsky, N. (1914). Yakut puzzles, proverbs, Christmas fortune-tellings, rites, beliefs, legends and others. Collected with the close participation of Kulakovsky, A.E.

Troshchansky, V.F. (1903). The evolution of the black faith (shamanism) among the Yakuts. Kazan: Typo-lithography of the Imperial University.

Vitashevsky, N.A. (1916). On the fairy tales collecting. Living Antiquity, 25. 